\title{
ME, YOU, AND US: CONSTRUCTING POLITICAL PERSONA ON SOCIAL NETWORKS DURING THE 2015 UK GENERAL ELECTION
}

\author{
BETHANY USHER
}

\begin{abstract}
This article offers statistical and discourse analysis of political leaders' profile pages during the 2015 UK General Election 'short campaign' as means to better understand the construction of political persona on Social Network Sites (SNS). It examines this as a group production and promotional activity that variously used patterns and routines of both traditional and digital media to display leaders as party branded selves. Performances strived for balance between authority and authenticity, using the political self as a spectacle to direct microelectorates to specific actions. This study demonstrates how self-storytelling is shaped by the coded conventions or "house rules" of SNS, which are viewed as inescapable institutions for maintaining public visibility. It examines how linguistic and visual elements, linked to different political ideologies, chimed with Twitter and Facebook users and looks to the impact on political campaigning.
\end{abstract}

\section{KEY WORDS}

Persona; Social Networks; Political Marketing; Celebrity; Microelectorates; Authenticity; Authority

\section{INTRODUCTION}

Described by journalists as the first 'social media election' (Bell), the 2015 UK 'short campaign' of March $30^{\text {th }}$ to May $7^{\text {th }}$ offered complex performances of political identity in digital space. Alongside the inclusion of the leaders of smaller parties in televised debates, this increased public visibility for leaders of seven political parties instead of the traditional 'Big Three' of Conservatives, Labour, and the Liberal Democrats. This research focuses on the textual and still image components of the leaders' Twitter and Facebook profiles-the only two platforms used by all-to establish how they helped construct their online identities. ${ }^{i}$ It examines "intercommunication" between long-established discourses of mainstream "representational" media-such as journalistic coverage as influenced by the marketing of celebrities-and the "presentational" techniques of DIY celebrities, who use Social Network Sites (SNS) to build fame through self-display (Marshall, "Mapping" 160-161). Presentation of political identity is explored as a group activity, aiming to motivate the electorate to specific actions, both online and in the voting booth. 
This study aligns with Mackey's (85-86) definitions of discourse and identity in examining how discourses, as the linguistic and visual conveyance of ideas and ideologies, "economically [...] concretely, objectively" construct political personas. Barbour and Marshall identify the intentional "presentation of specific identity" from the "composite of multiple selves" as the basis for studying persona ("Constructing Persona"). The short campaign offers a focused timeframe to examine how persona is constructed and managed through the capture of real-life 'experiences' (such as on the campaign trail), displays of agreement with the electorate and the purposeful use of other discourses, such as journalistic coverage or manifesto pledges. Coleman argues that during campaigns, political leaders are both the "scene-setters [...] [and] the script editors," using storytelling to appear "close to us" (169). This article examines selfnarrative as group production practice to argue that, as with celebrities and microcelebrities, politicians aim to create parasociality with the electorate in order to "compete for the largest number of listeners...with page views and clicks synonymous with success" (Marwick 347).

The short campaign was a period of heightened activity, but its specific parameters offers opportunities for broader insights into focused, goal-driven presentation of identity. SNS content is not viewed as inventing reality, but as connecting and reframing real events with a view to build a "branded self," as described by Alison Hearn (2013a and 2013b). Political persona is produced for public consumption, using individualism and self-promotion to generate "rhetorically persuasive packaging, its own promotional skin" ("Sentimental Greenbacks" 27). Examining the construction of political persona in this way also offers insights into how SNS have reshaped political communication, which Kriess identifies as an underresearched area of study (132). He argues for greater scholarly conceptualisation of how "retweets and sharing campaigning content...may be a highly meaningful or consequential form of political speech in terms of inadvertent exposure" and the relationships between SNS and mainstream media during election campaigns.

\section{FRAMING POLITICAL PERSONA CONSTRUCTION ON SNS}

There are numerous studies of the relationship between media and politics, often building from Shumpeter and Downs mid-twentieth century examinations through the lens of business economics and marketing. Scholars such as Marshall (Celebrity and Power), Meyer and Hinchman, Corner and Pels, Street, and Turner argue variously that the political leader should be viewed in relation to the logics of celebrity culture-that is, as a commodity presented and negotiated through the systems of public relations and marketing-and how this relies on attracting news coverage. In 2010, Kellner used Debord's Society of the Spectacle (1967) to demonstrate that US presidential campaigns are "subject to the logic of spectacle and tabloidization in the era of media sensationalism, infotainment, political scandal" (117). SNS offer new vehicles for campaign teams to manufacture political personas which "embody the sentiments of the party, the people and the state in a similar way to [how] celebrity has to embody the beliefs and attitudes of an audience" (Marshall, Celebrity and Power 203). The success of politicians, and by extension their parties' publicity teams, is now judged not only by column inches and polling, but also by increased followers, shares and comments. SNS are not simply platforms for expressions of the politician as an individual, but are formalised within the structures of political marketing as group production activity.

Self-display as group production also shapes celebrity use of SNS. My 2015 examination of the Top 20 celebrity Twitter accounts found 65\% were team produced, with public relations professionals having some involvement in the construction of content-a significant increase on the 13\% found by Marwick and boyd four years earlier. Both Marshall ("Mapping") and Turner identify this as influenced by the production processes of microcelebrities. Hearn's work around 
the branded self, most recently in terms of reality TV 'stars', demonstrates the way workers use their sense of self-not only the public face, but also the private and emotional-to build public visibility. However, these studies usually consider the ways in which individuals use SNS platforms. While Marwick, boyd and Senft each explore the dynamics of personal branding and strategic self-commodification, their work focuses primarily on the individual with the influence of public relations and marketing teams seen as an exception rather than a rule. Similarly, Zizi Papacharissi focuses on the individual as the principal performer, specifically examining how Twitter enables "condensed performances of self" for a variety of actual and imagined audiences. She claims that success relies on shifting the emphasis from "stability of the self (self as object) to change of the self (self as process)" (1992). Explorations of microcelebrity as a cultural phenomena argue that opportunities for direct, individual-to-individual dialogue is crucial to self-construction, which builds public visibility. To expand this to the world of 'political celebrity' emphasises Street's discussion of how, through mediated public performance, politicians "try to demonstrate certain political qualities and connect them to political values" (446). Microcelebrity, in this context, is therefore understood as a production mechanism through which politicians can build a following, enabling them to extend their message and reach members of the electorate who may not engage with mainstream representational media.

Studies identifying how domestic UK (Auty and Cowen, Gibson and Ward, Gibson et al) and international (Baxter et al, Gibson et al, Jankowski et al) politicians use social media often focus on opportunities for increased dialogue as enabling the public sphere. Michael argues that social media could support the development of a more "collaborative political culture," but "any such process would require authenticity on the part of politicians, informed contributions from the public, and a willingness to engage from both" (46). However, many studies conclude that politicians are only symbolically interactive and reluctant to engage in "open, dynamic forms of electronic communication with the electorate" (Baxter et al 465). Indeed, Ross, Fountaine and Comrie claim part of the problem of proving the effectiveness of online campaigning is that it "under-exploits the very characteristics of social media's interactivity which could genuinely enable a real shift in political-public communication" (251-252). Kreiss argues that empirical research into online political communication has found that its potential for allowing deliberation to reshape democratic process is overstated. He identifies how few voices are heard and that the professionalised mechanisms of media not only set the agenda but also offer rare opportunities for real audience discussion (118-135).

However, it is not only dialogue that enables users to contribute to the construction of other people's online personas. Marshall (Mapping 163) argues that celebrities use micropublics-audiences centralised around their image-to support the social construction and maintenance of their profiles. Thus, it is important to understand how campaign teams attempt to channel what could be described as microelectorates to displays of agreement, which are shaped by the coded construction patterns of SNS. As members of a leader's social media team choose which members of their microelectorate to respond to, the "older processes of broadcasting/receiving images and the hierarchies of stardom/fandom may prevail" (Thomas 2), but simple displayed agreement has become crucial to political communications on SNS.

Kreiss argues that political communication on SNS looks much the same as offline, specifically in its use of "emotional, moral and partisan appeals" (125). Next, I'll explore how the construction of SNS political persona aims to create parasociality with the electorate. Examinations of how SNS have expanded Horton and Wohl's initial concept of parasocial relationships, such as those undertaken by Marwick, boyd and Senft, often highlight two things: how SNS offer symbolic opportunities for both direct dialogue and for tantalising glimpses of 
the 'private self' behind the public mask. In "Twitter and the Celebrity Interview," I argued that parasocial interaction, defined by David Giles as "the activity that takes place during the act of media use itself" (95), now includes planned opportunities to jointly engage in production processes of promotion -in that instance, journalistic interview moments. This, of course, expands parasociality away from being a one-way activity to one formed through mutuality of production. I want to expand this further to highlight how, by sharing, liking and commenting on stories, members of microelectorates help create and maintain the visibility of political personas. While audience appraisal may not always be positive, criticism also increases visibility and extends message. However, the coded commands of SNS primarily work to encourage the demonstration of agreement and given that the posts I address are produced with the aim of encouraging displays of support, this will be my primary focus.

\section{Patterns and Routines of the Performance of Political Persona on SNS}

Mackey argues that for public relations' professionals, identity is solid, real, and aims to create images in the minds of the observers. However, he highlights that there is a distinction between "how a person is" and "how they are thought of" (85). Mackey's use of 'how' rather than 'who' a person is, emphasises the importance of identity as a constructed discourse before observers. SNS performance aims to establish a fixed, authentic identity for the political leaders. Mackey, like many others (see Barbour and Marshall's discussion in "Constructing Persona"), argues the usefulness of Erving Goffman's 1956 The Presentation of the Self in Every Day Life in examining persona as a conscious performance. Goffman identified performance as "a period marked by [...] continuous presence before a particular set of observers" (13), which aims to influence them in some way. If it can be replicated, then a pattern or routine can be formed. Of course, as Mackey identifies, this language translates easily to the performance of self on SNS. The 38 days of the short campaign produced a total sample of 3,177 tweets and 1,033 Facebook posts, which were coded using both Seartwi analytics and manual methods to identity the kinds of patterns and routines Goffman highlighted as crucial to understanding persona construction.

Figure One: Levels of SNS activity during Short Campaign
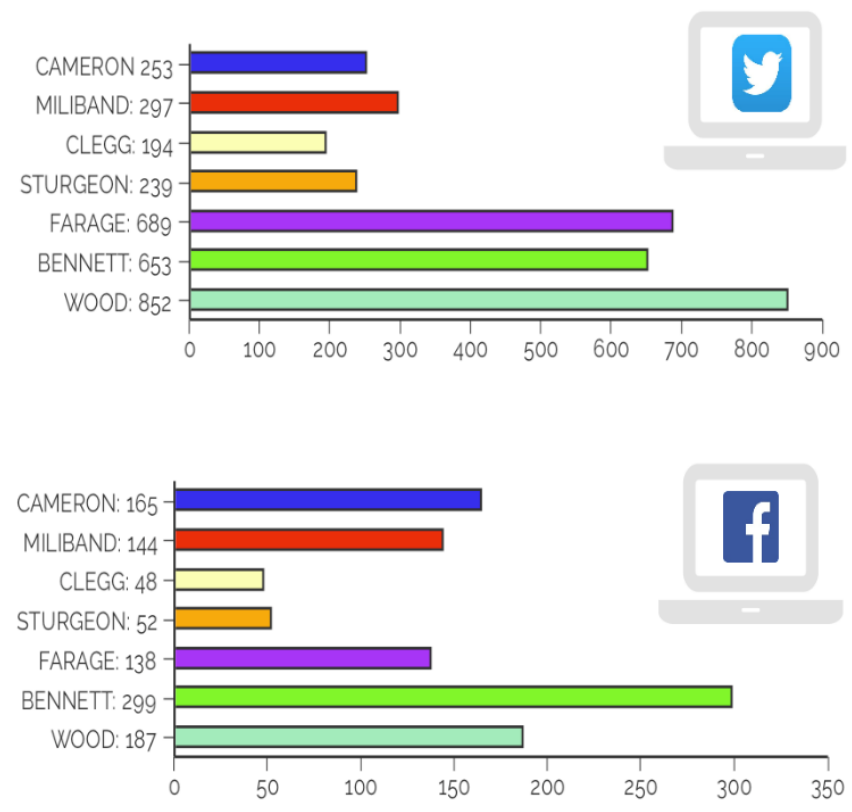
Coleman argues digital technology is used in the service of "political aims that take shape in institutionalized contexts" of electioneering as a storytelling practice (174). Using the SNS profiles of political leaders to tell the story of electioneering is now key to political communication, as demonstrated by levels of SNS content. While engagement varied, all leaders had consistent presence. Twitter was most popular platform with several tweets every day. Two leaders (Clegg and Sturgeon) used Facebook more sparingly than the others, offering content first shared on other online platforms. Only Sturgeon's team (at times), produced posts in third person rather than first person self-narrative, describing experiences on the campaign trail specifically as would be written by a journalist. The two political leaders with the smallest 'official' campaign teams and campaign budgetsii (Natalie Bennett and Leanne Wood) produced the largest amount of content overall and there was significant similarity in their production patterns. On Twitter and Facebook, they usually reposted content from other users with simple, short comment above. This is a rapid posting pattern, achievable by an individual.

Goffman argued the construction of persona can either be sincere, where the performer believes "the impression of reality which he stages is the reality" (Presentation of Self 10), or cynical, only aimed at influencing the audience to a specific end. Performances are "moulded to fit into the understanding and expectations of society" (23) and will tend to "exemplify the officially accredited values of the society" (24). Of course, Goffman's works discussed physical rather than virtual environments, and this was extended in his paper The Characteristics of Total Institutions, given a year after Presentation of Self was first published. There, Goffman described how "we tend[ed] to sleep, play and work in different places" (Total Institutions). SNS now amalgamate the last two categories for all those whose careers rely on negotiating public visibility. Viewing SNS as institutions with similar "house rules," privileges, and functional requirements as highlighted by Goffman, focuses attention on the significance of consistency in the way SNS are updated. The levels of discourse in Figure One reflect that political party marketing teams see SNS as significant institutions for campaigning, which, like other societal and media institutions, have conventions. These undermine the personal autonomy we may "expect to exert over [...] interpersonal environments and may produce the terror [...] of being radically demoted" (Goffman, Total Institutions) through a decrease in followers or only few shares or likes of a post. For public figures, SNS are primarily workplace institutions as compared to institutions of play for most users. For many, such as politicians, microcelebrities or journalists, they are currently inescapable institutions and crucial parts of maintaining visibility. Therefore, following Goffmanian logic, performances are both cynically produced and very controlled.

Political public persona on SNS straddles lines between authority as public figures and authenticity as users. In Consumers, Arnould, Price and Zinkham examined the relationship between emerging bloggers and digital consumers, arguing that threads of authenticity and authority weave together, but fundamentally the authoritative voice is paramount in influencing consumer choice. For Goffman, no person is ever really authentic in public, but always governed by institutional rules and patterns. Expanding these discussions to political leadership highlights it as a vertical operation of persona construction, with the authoritative voice outweighing an authentic one. Success depends on constructive use of the conventions of SNS, created specifically to enable the presentation of identity. In the next section I consider how the differing "house-rule" coded conventions of Facebook and Twitter helped shape the construction of political personas when using intertwining demonstrations of authoritative voice and displays of authentic self. Twitter allows just 140 characters per tweet, quick and easy sharing of other people's tweets, and instant replies. Facebook allows unlimited text per status update and talking space directly beneath, but also quick demonstration of agreement through 
'likes'. Therefore, analysis of how these performances build political leaders' brands through parasocial display needs different focuses.

\section{BUILDING BRAND THROUGH BOND: PARASOCIALITY THROUGH WEAVING AUTHORITY AND AUTHENTICITY}

Visualising both the routines and textual discourses of Twitter activity (Figure Two) illustrates how the short campaign was a period of intensive performative activity around the image of political leaders. All seven produced more 'Status Updates' than any other kind of tweet, therefore following a broadcast model of tweeting. However, all seven also interacted directly with followers either through replies or retweets. Miliband and Cameron interacted with their audience the least, while the three female leaders-Sturgeon, Green, and Wood-did so most. Bennett and Wood were also amongst the most prolific tweeters, averaging 17 and 22 tweets a day respectively. Farage and Miliband did not reply to followers on Twitter at all and, despite being the most interactive party leader when also factoring in retweets, Wood barely did so either.

Figure Two: Statistical analysis of leaders' tweets and text cloud of discourse during final week

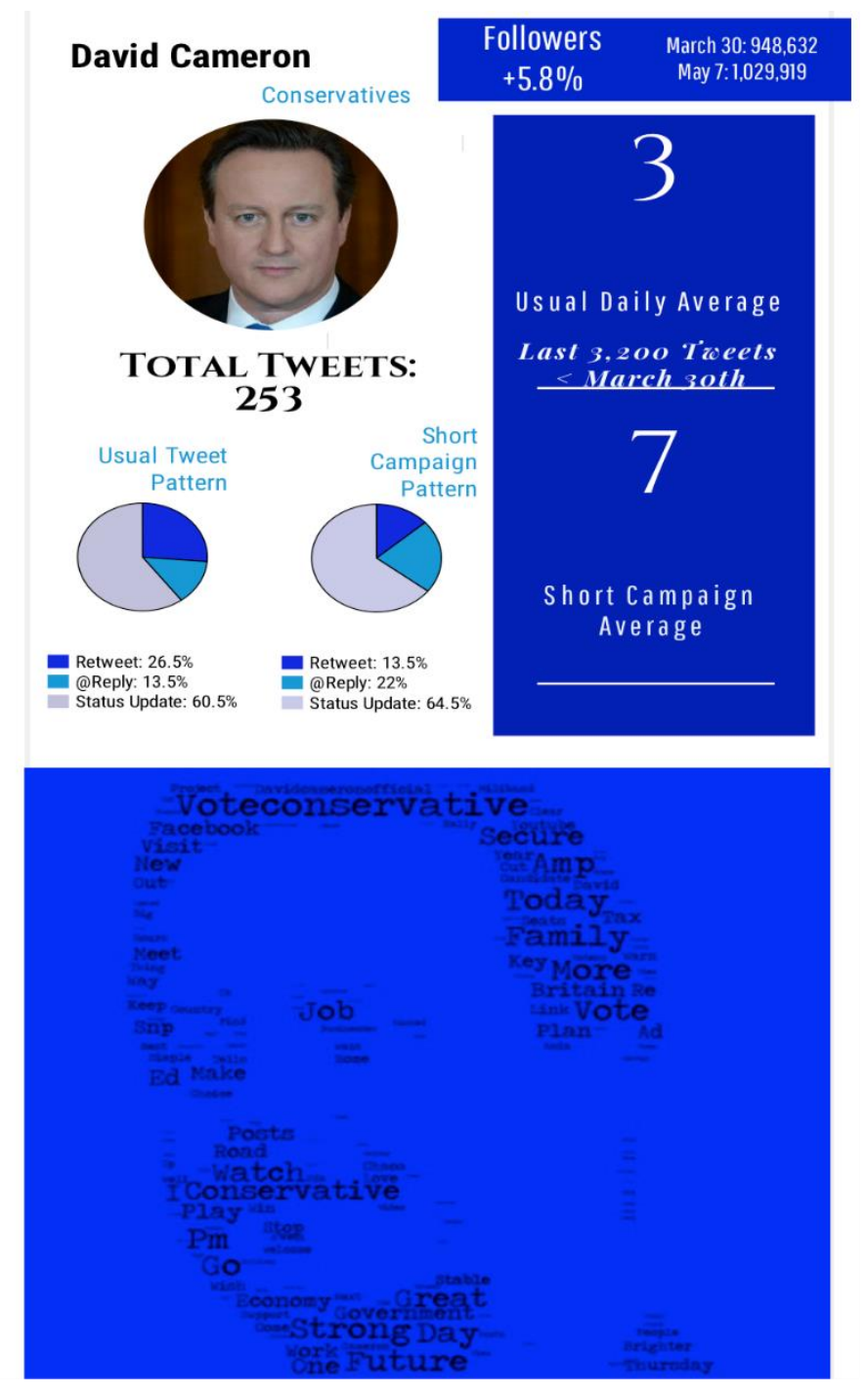




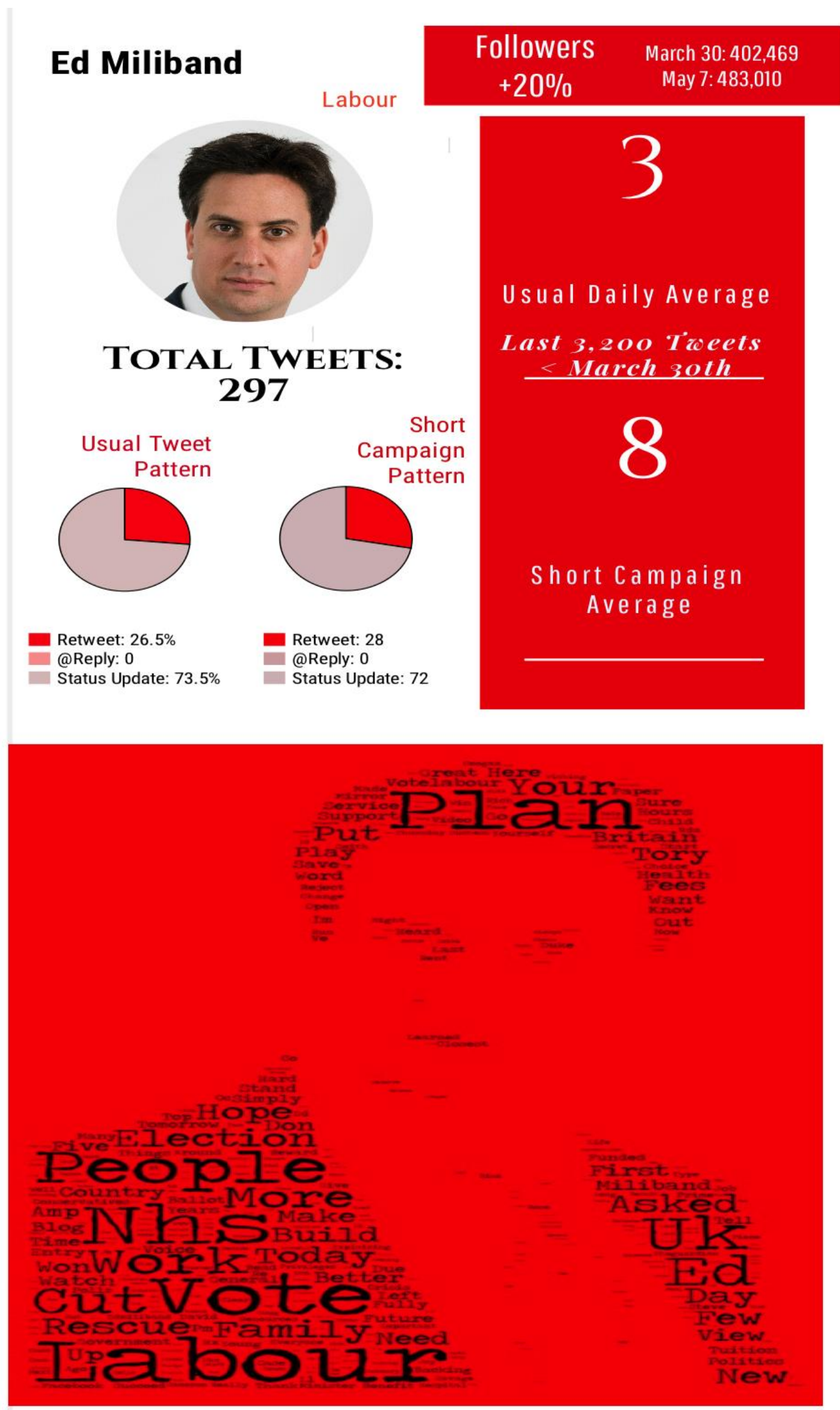


Nick Clegg

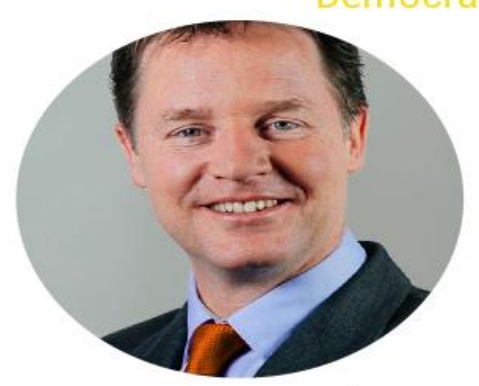

TOTAL TWEETS: 194

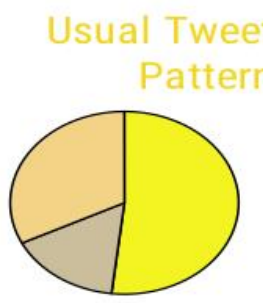

Retweet: $57 \%$

@Reply: $17.5 \%$

Status Update: $35.5 \%$
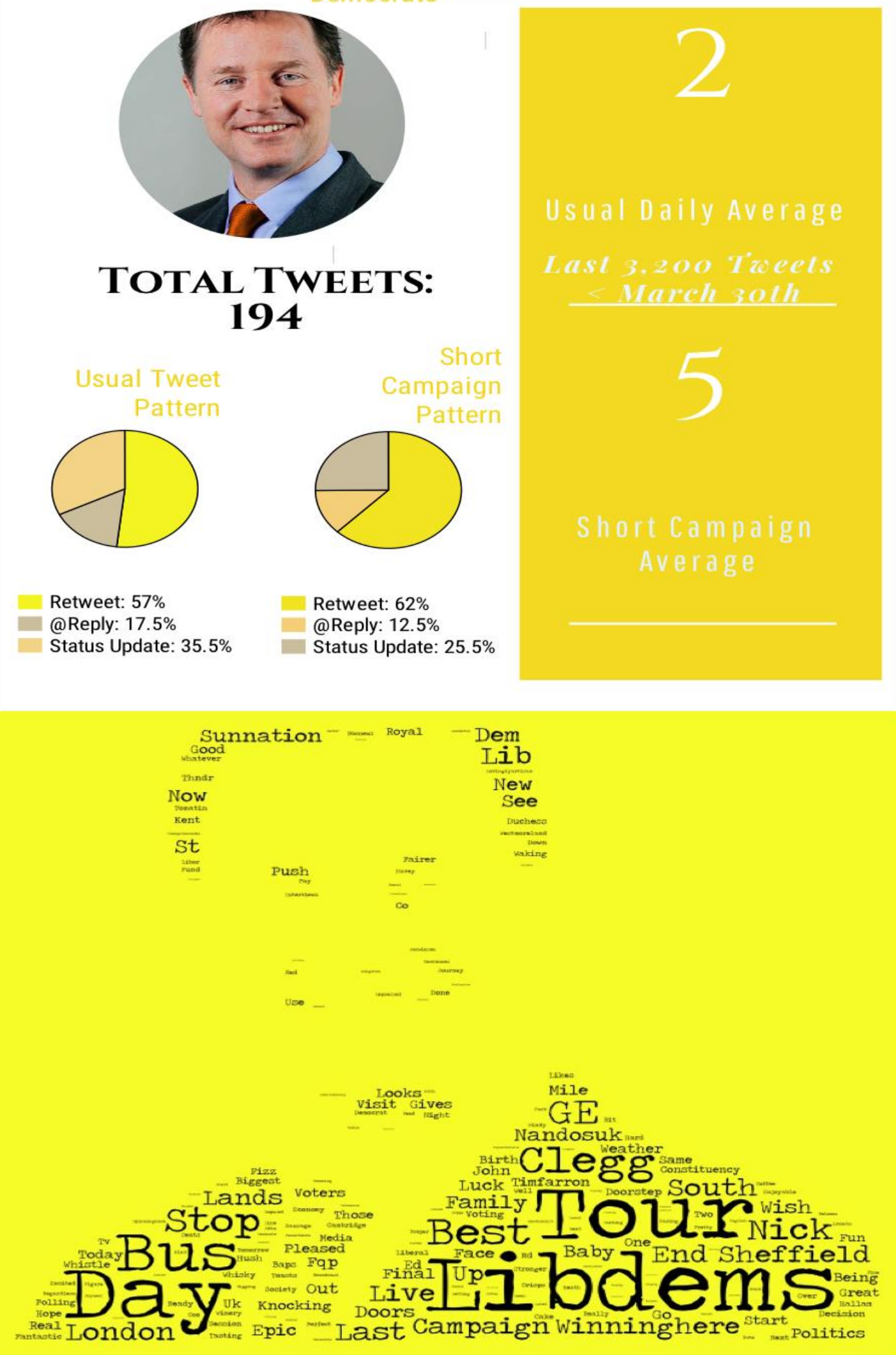

Retweet: $62 \%$

@Reply: $12.5 \%$

Status Update: $25.5 \%$ 


\section{Nicola Sturgeon}

Nationalist

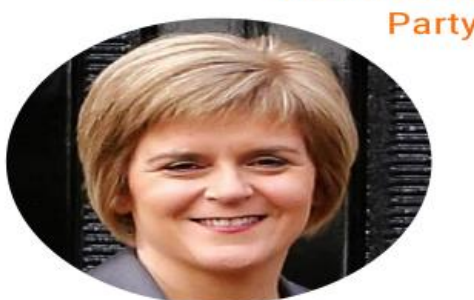

TOTAL TWEETS: 239
Usual Tweet

Pattern

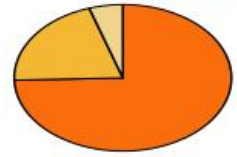

Retweet: $74.5 \%$ @ @eply: $20.5 \%$

Status Update: $5 \%$

$\begin{array}{cc}\text { Followers } & \text { March } 30: 135,514 \\ +30 \% & \text { May } 7: 196,388\end{array}$

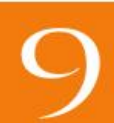

Usual Daily Average

Last 3,200 Tzeets March 30 th

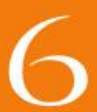

Short Campaign Average

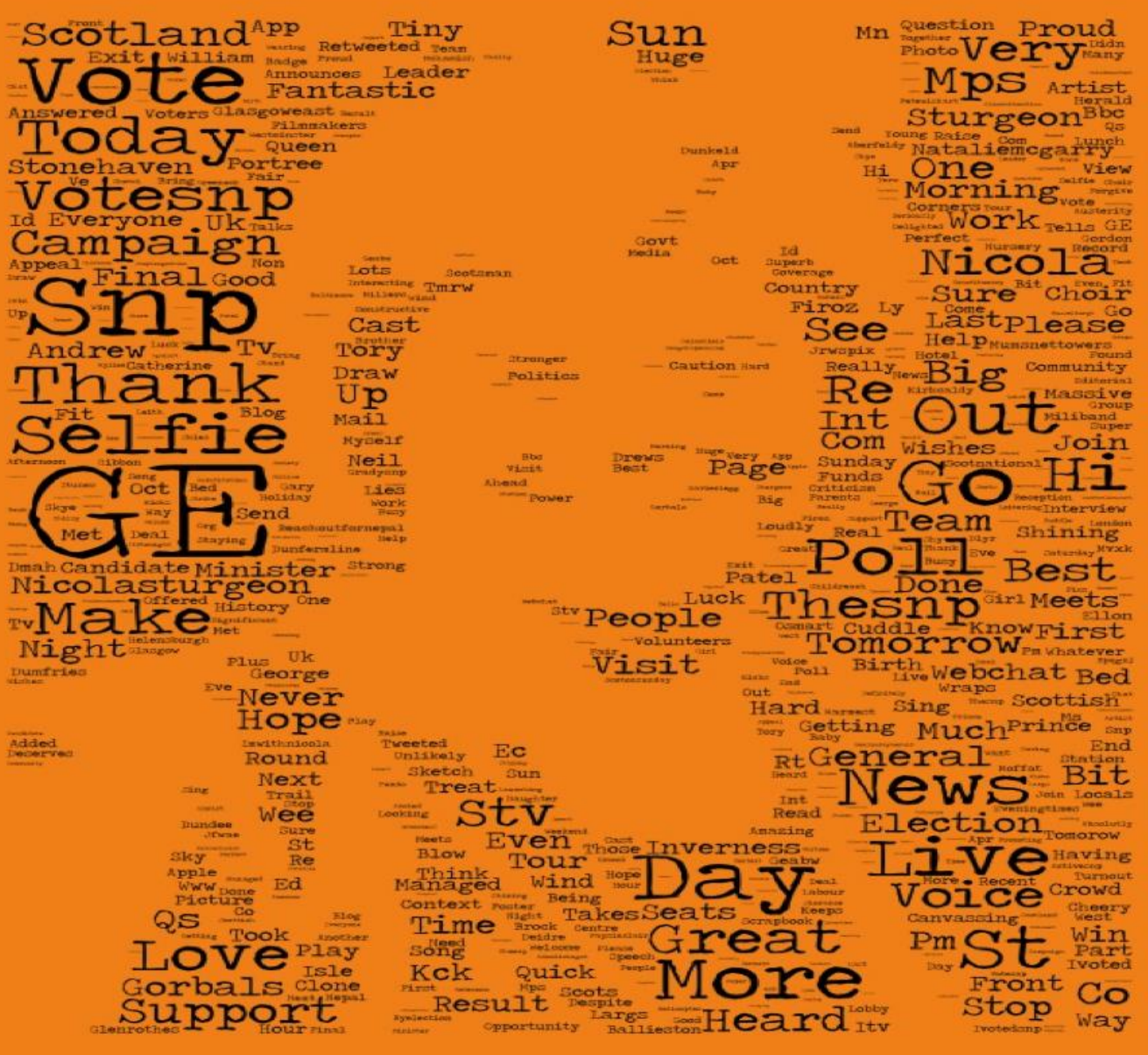




\section{Nigel Farage}

UK

Followers
$+13 \%$

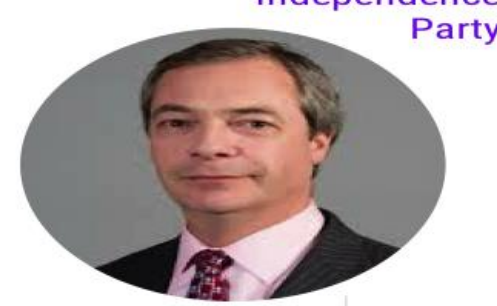

TOTAL TWEETS: 689

Usual Tweet

Pattern

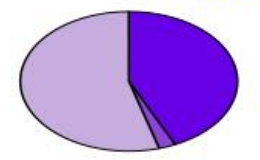

Retweet: $43 \%$

@ @eply: 2.5\%

Status Update: $54.5 \%$

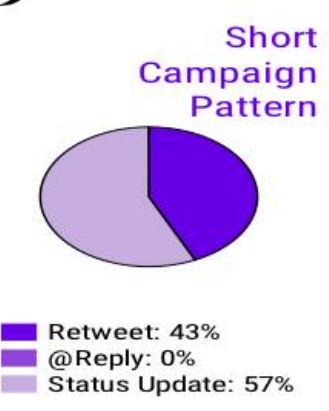

Usual Daily Average

Last 3,200 Troets March soth

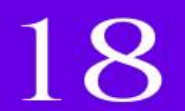

Short Campaign Average

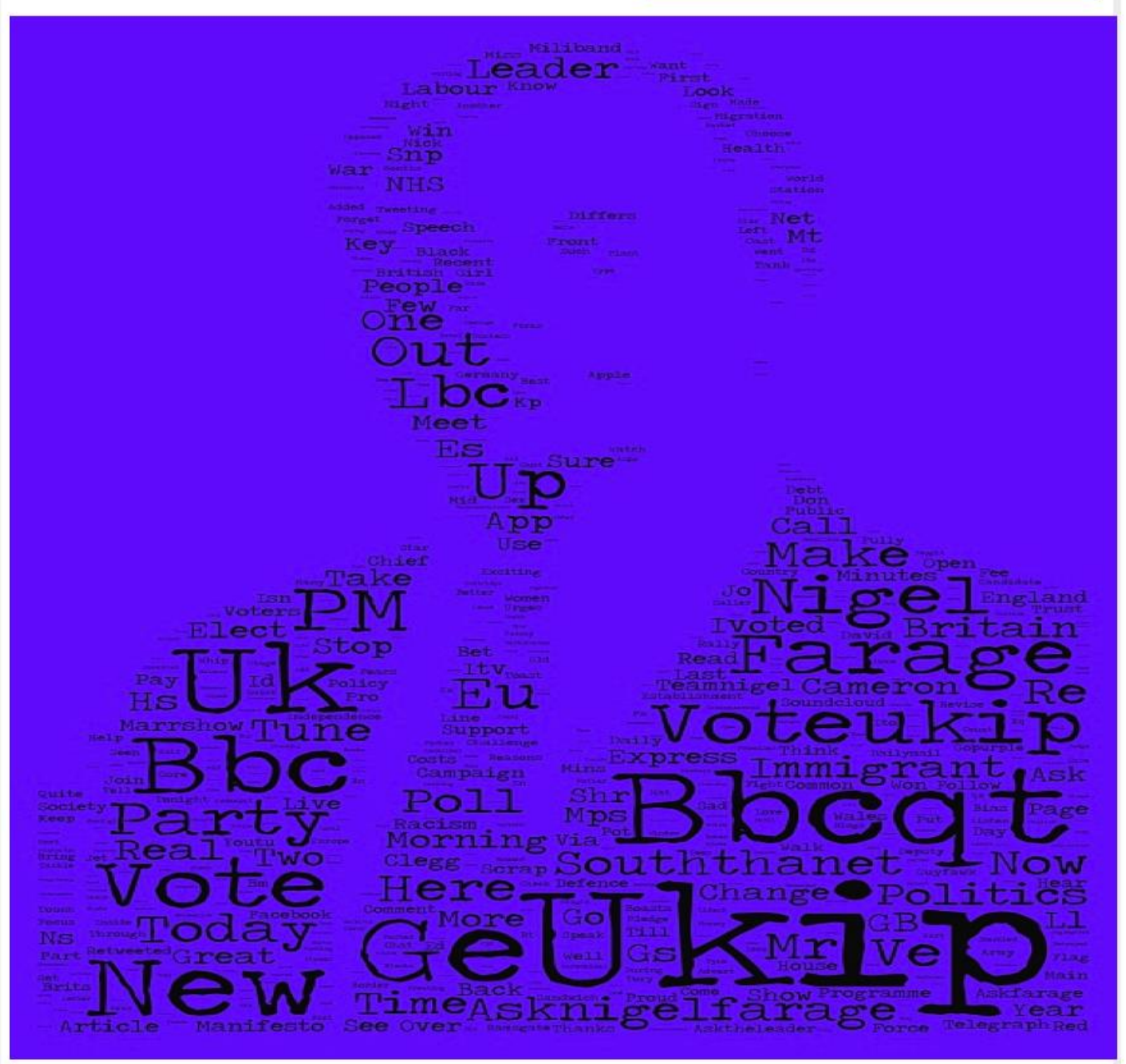


Natalie Bennett

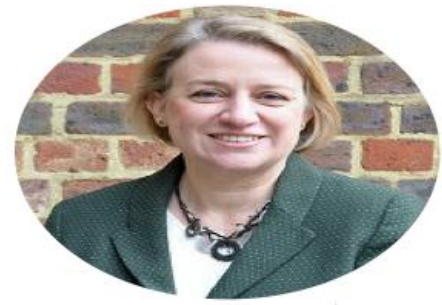

TOTAL TWEETS: 653

Usual Tweet

Pattern

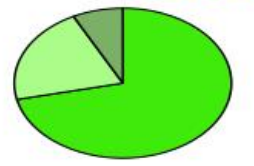

Retweet: $71.5 \%$

@ @eply: 21\%

Status Update: $54.5 \%$

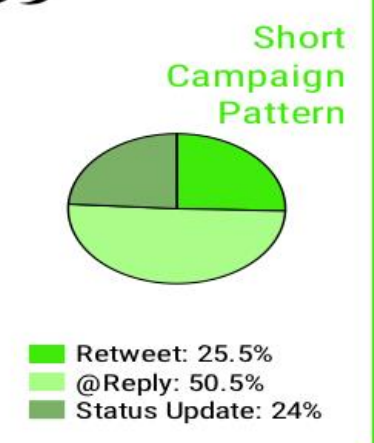

Followers March 30: 54,704

$+33 \%$

May 7: 81,805

\section{1}

Usual Daily Average

Last 3,200 Troeets March solle

Short Campaign Average

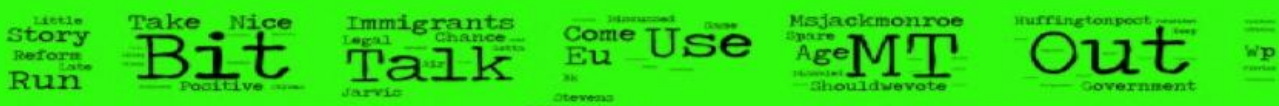
Watch Today
Done Toung

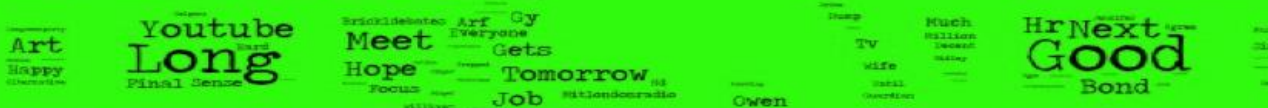
Work
HiSt Molborn

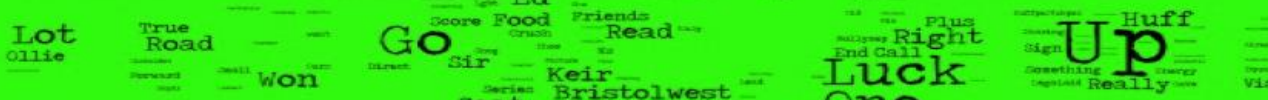

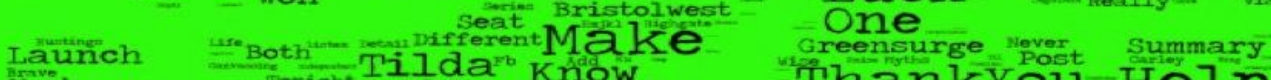
Launch " ioth Tilda Know - Adaed - Bennett

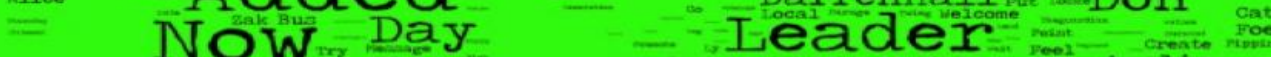
wrone 1 Show climate wrong Show week Iive Cambridgo BBCUKMet $=$ Pop Voteritineon

Huge Team green

moverty GHinjiew Ieadili voter neor-Amelia IaIty PIay Teli- Interview molitics

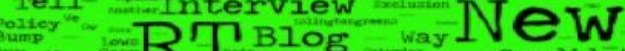
m 1 Mlog way 1 candidat

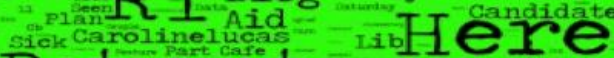
nar Retweet - Cameng $V$ keyte Hear

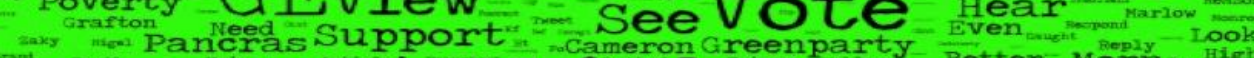

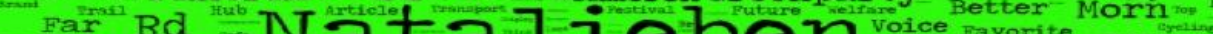

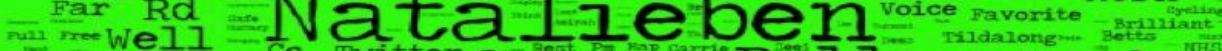
year schoolFledge wil Ukip save First Jones Thegreenparty 


\section{Leanne Wood}

\section{Followers $+45 \%$

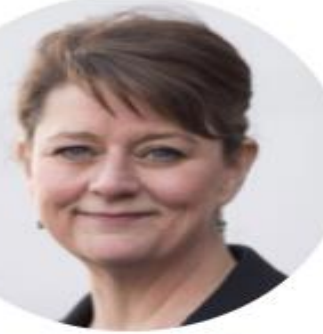

TOTAL TWEETS: 852

Usual Tweet

Pattern

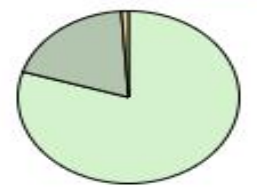

Retweet: 79\%

@Reply: 19\%

Status Update: $1 \%$
Short

Campaign

Pattern

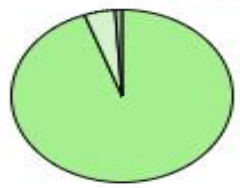

Retweet: $94.5 \%$

@Reply: $4.5 \%$

Status Update: $1 \%$

\section{Usual Daily Average}

\section{Last 3,200 Troets}

< Mareh soth
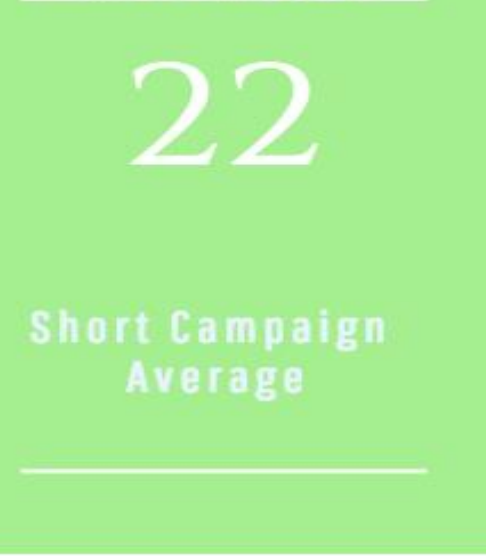

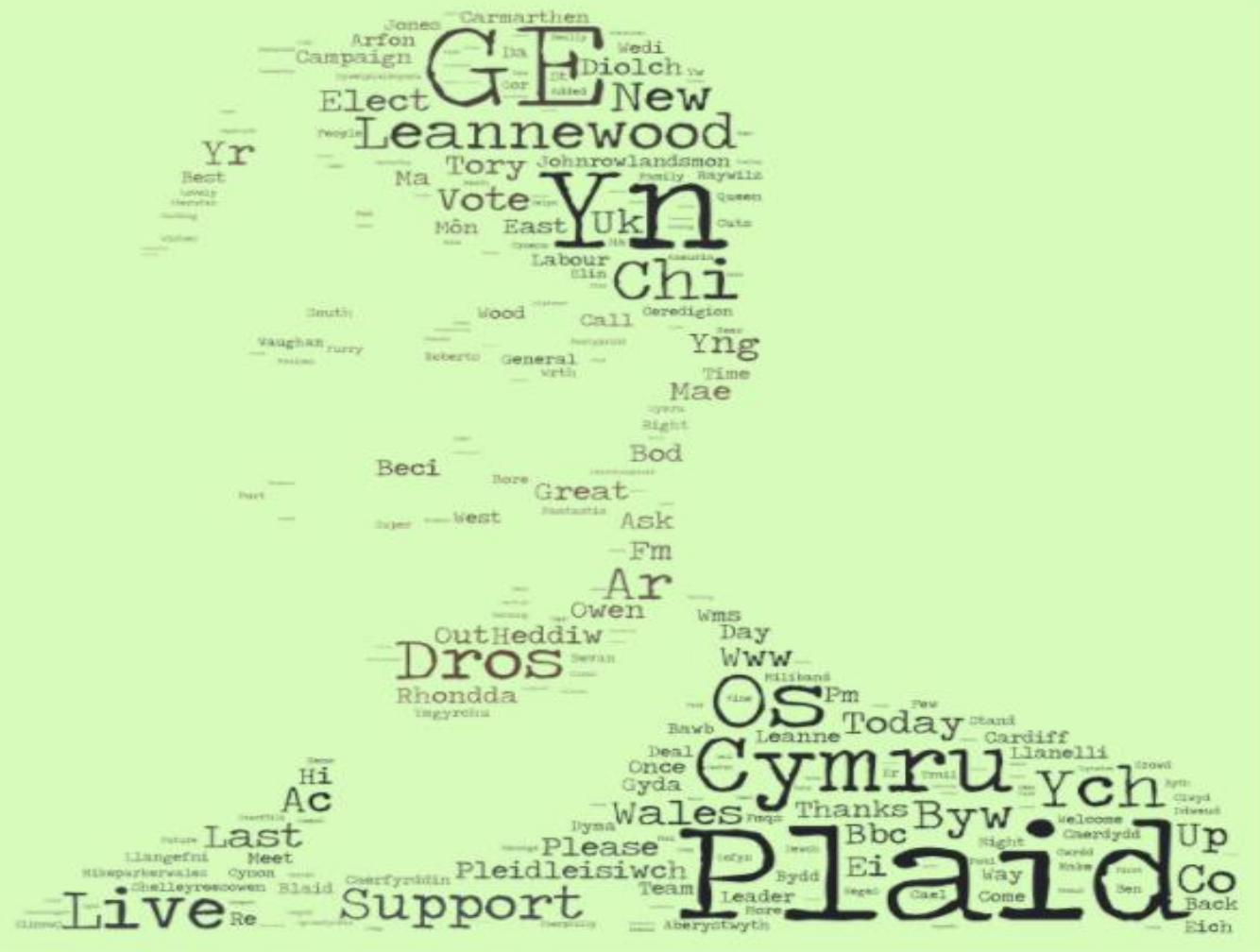


Production patterns varied, but there was one central dynamic-the leaders were positioned alongside "others, as particular kinds of people" (Bucholtz and Hall 259). Rather than actively engage in debate and dialogue with the electorate, interactions used the display of mutuality of stance to demonstrate popularity. Coupland and Coupland argue stances are "clearly hooked into wider social discourses and ideologies, or are contextualized in important ways by them" (228). Interactivity was used to demonstrate immediate identification rather than to engage in real dialogue and so the authority of the political leader's voice dominates. For SNS users, indications of mutuality of stance happen quickly over single interactions (liking or sharing a post/tweet) as described by Du Bois, over multiple interactions (commenting or discussing beneath a post/tweet), and "intertextually" as described by Damari (such as sharing news or other evidence). Visualising the text of tweets of the seven leaders offers interesting insights about how the dynamics of self-branding influence political communication.

For Miliband and Cameron this was approached consistently and narrowly, linked to specific political ideologies and to "the family". Despite each having a similar number of tweets to Sturgeon, for example, they used a far narrower range of words. iii Cameron focused on neoliberal discourses of security ("strong", "secure") and the economy ("economy", "jobs"), imparted a sense of immediacy ("today", "future") and linked directly to the "family." Miliband used similar techniques in terms of the personal ("family", "people") but linked to the socialist ideal of universal health care ("plan", "rescue", "NHS", "cut"). While differing in ideological focus, their campaign teams approached promoting their personalised brands in remarkably similar ways, both in terms of the levels and structure of tweets. Coleman argues campaigning politicians aim to "represent citizens" through addressing people "as if they would know what moral category they belong to" (172). Cameron and Miliband's use of "family," specifically aimed to define "the terms of moral conflict" through "simplicity of narrative [and] their relationship to practical consequences" (172). Their performance of stance aimed to construct political personas that embodied sentiments of the electorate, party, and state (see Corner; Pels; Marshall). In short, the discourse of these leaders aims to bond the real-life concerns of microelectorates to their own political authority.

The density of the text clouds of Sturgeon and Bennett's discourses reflects far higher levels of retweeting of other people's comments. Prolific retweets or reposted tweets with brief framing means dozens of names appeared just once, and the terms "thanks," "thank you," "you," "I," "good," and "great" appear as key terms in their visualised discourse. These actions could be viewed as attempts to show not only mutuality of stance, but also an attempt to colonise the experiences and opinions of their microelectorate to advance visibility and therefore, voter accumulation. It aims for bonds of kinship - what Rojek describes as "fraternisation" (131-134) and Marwick and boyd refer to as "affiliation" ("To See" 147). Marshall ("Promotion and Presentation") argues that presentational media encourages and seduces individuals to more elaborately construct self as if engaging in a marketing practice. Hearn ("Producing Reality" 165) builds on this as well as Andrew Wernick's argument in Promotional Culture that all manner of communication can be understood within the contemporary cultural conditions of promotionalism. Persona creation on SNS, therefore, has as its function "some kind of selfadvantaging exchange" (Wernick, 181). Understanding political persona as a performance which aims to colonize the lived experience of the electorate in the interests of voter rather than capital accumulation offers another way by which the branded self can be understood as a "distinct kind of labour," using "highly stylized self-construction, directly tied to...promotional mechanisms" (Hearn, "Producing Reality" 165). This, like all types of brand management, relies particularly on consistency of message as evident in both the discourse used and the way production patterns are employed. Farage, Wood and Sturgeon consistently used nationalistic discourses to build their branded-self. Wood's profile achieved this linguistically through 
tweeting in both Welsh and English about the particular social issues facing Wales. Sturgeon linked emotive terms such as "love," "support," "proud" and "Great Day" to herself and the Scottish National Party (SNP) as positive representatives of "Scotland." Farage identified himself as the voice of the "UK" or "Britain," often directly in opposition to the "EU" and "immigrant." His self-brand was also built through the expression of distrust of establishment politicians and other authoritative voices (such as the BBC or expert opinion). He described them as in direct opposition to himself as an everyday "British bloke" longing for an escape from globalised multicultural society.

The Twitter accounts of the six leaders discussed so far have a common component: they always used public facing discourse and appearances to shape content. Tweets usually offered accounts and updates from the campaign trail and these often bore hallmarks of mainstream news coverage of election campaigns. For example, although posts were usually written in first person narrative, they also included sound-bites and candid 'press-photographer' style pictures. Some tweets were constructed like news introductions, including descriptions of the 'who' 'what' 'where' and 'why' of leaders' public appearances and thus using journalistic conventions for constructing reality to give content authority (see Tuchman Making News). Other shared material existed elsewhere too, such as party manifesto pledges or political broadcasts. Essentially, public authority outweighed private authenticity in terms of impact on the content chosen and how it was displayed.

By contrast, Nick Clegg's Twitter account primarily offered behind the scenes glimpses from the campaign trail. His Twitter feed used self-presentation and "strategic intimacy" in a similar way to how microcelebrities build visibility in relation to fans, as described by Senft ("Microcelebrity"). Looking at his text cloud, key terms include "day," "bus," "stop," "best," and "tour." There are also a number of singular references to the food he ate between appearances, including meals from the restaurant chain "Nandos," which often offers free food to minor celebrities in return for tweets. Clegg's tweets made few directives to 'vote' to his followers and very little reference to Liberal Democrat policy, instead offering moments you would not be privy to through traditional representational media's coverage of campaigning. Marwick and boyd argue that the success of celebrity performance on Twitter is reliant on backstage access. Turner argues microcelebrities "borrowed from the publicity and promotions industry" and have in turn "been 'borrowed back' by the 'real' celebrities" (74). Clegg's persona construction offers glimpses of 'ordinary life' to place his "fame on a continuum, rather than as a bright line that separates" him from his followers (Marwick and boyd, "To See" 141). Clegg was the first of the political leaders to use SNS as part of campaigning, with the display of private moments on both Twitter and Facebook key parts of what was described as "Cleggmania," during the 2010 election campaign (see Tolson, "Hope Springs"). However, by 2015, it appears that the structures of the political marketing machine have turned political communication on SNS into, primarily, another exercise in establishing authority, with Clegg's approach now appearing to be out of place. Indeed, in terms of likes and followers (see Figure Five)-and later at the ballot box-Clegg's approach of placing authenticity over authority, did not serve him well.

Given the way Clegg and his team embraced personal narrative on Twitter, it is curious that they all but abandoned Facebook - a site which encourages revelations of the personal through its coded commands. Figure Three identifies correlation between levels of visibility on Facebook and personal models of linguistic performance, where political policy is framed as direct conversation. Facebook offers a way of measuring the size of public spheres (via indications of the number of people 'talking about' a topic) based specifically around individual users. While, of course, the number of followers the leader has on the site is a variable, there is clear parity between the use of first person narrative ("Me," "I") linked to both mutuality ("We," "Us," "Our") 
and direct addressing ("You," "Your") of the microelectorate. Linguistically, posts often paired these phonetic and sematic representations to create symbolic bonds. This is evidenced in the way political performers and their campaign teams use personal pronouns when putting content on to Facebook-a technique discouraged by Twitter's textual constraints, as pronouns are often sacrificed for information. The continuous use of personal pronouns by Cameron, Miliband, and Farage particularly established a dialogue of selfhood, which Rojek (130-133) identifies as a key to maintaining public visibility. However, this too is only symbolically interactive, aiming for the same displayed agreement as explored during analysis of Twitter profiles. It appears to be a successful technique. These three political leaders had the largest number of people talking about them throughout the short campaign, often amounting to more than five times the number talking about the other four political leaders at any one time.

Figure Three: Use of personalised pronouns related to number of people 'talking about' leaders on Facebook

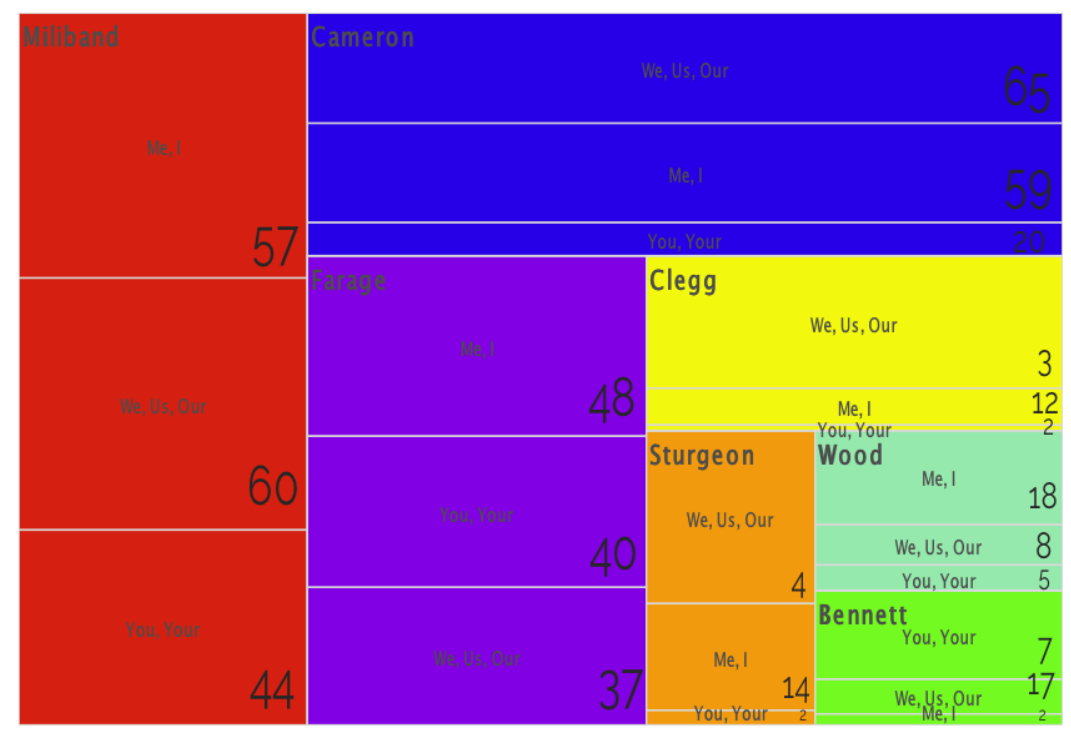

\section{The personalised public sphere: People 'talking about' Political Leaders on Facebook}

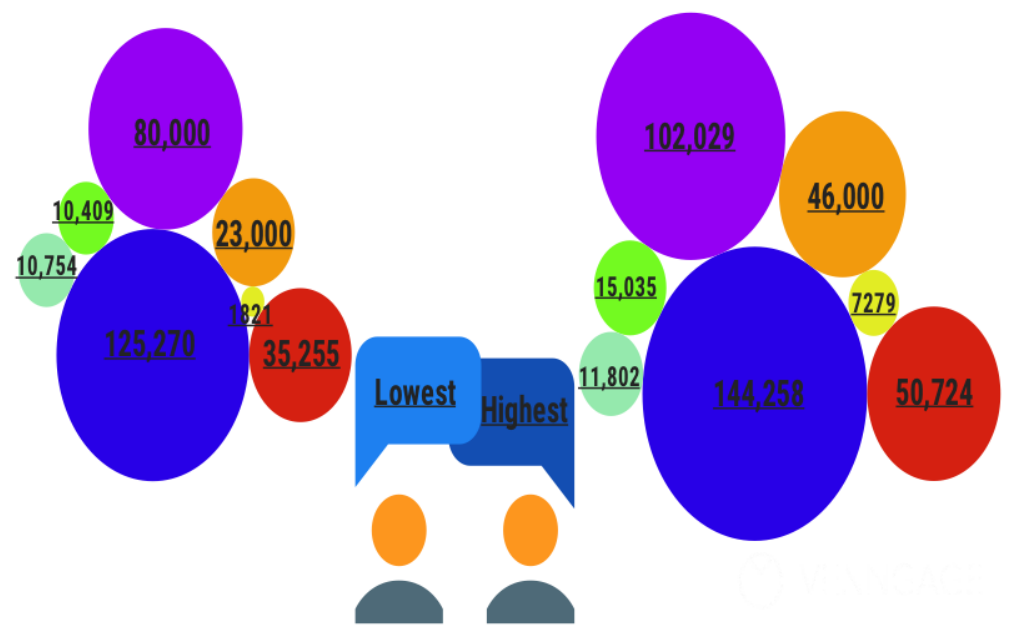


Using first person narratives and speaking directly to the microelectorate as individuals, when linked to right-wing news coverage of immigration, appears to have proved a particularly effective way of getting people "talking about" Nigel Farage. As shown in Figure Three, he was often discussed on Facebook more than the leaders of all other smaller parties combined. In Understanding Media, Marshall McLuhan identified printed media as establishing and perpetuating nationalistic discourse. He argued that printed media reconstructed the "human dialogue on a world wide scale," and the result was "nationalism, industrialism, mass markets" (188). Typography and mass media allowed political unification of populations through vernacular and language groupings. Nationalism, therefore, "depends on the press" extending and replacing the tribe with "an association of men hegemoneously trained to be individuals" within a nation (192). On SNS (and beyond), Farage acted as a nationalistic mouthpiece, using what could be described as digital dog-whistling to attract and maintain an audience. For Anthony Giddens, McLuhan's work established human experience as “inseparable from its own media: the printed text and subsequently the electronic signal" (24). He argued the "media does not mirror realities, but in some part form them" (27), re-organising "time and space" so experiences which are "rare in day-to-day life...are encountered routinely" (24). This in turn helps shape our understanding of our lived experience. Despite refugees rarely committing crime, tabloid newspapers disproportionately report on those who do. The Daily Express, whose owner Richard Desmond financially backed UKIP, was used consistently as part of the construction of Farage's Facebook page, linking his persona to the far-right agenda of the publication. Identifying immigrant crime as a risk to all, and therefore a reason to get out of the European Union, was a key discourse. Under the banner 'Make Britain Great Again', his Facebook page co-opted nationalistic discourse and opposition to "others," via the use of news as evidence, to help form his online persona. His page also often invited audience members to like or share posts if they 'agreed'. This worked particularly well in terms of increasing his visibility during the short campaign and beyond, with Farage not only having a larger number of people talking with him (of course many condemning his nationalistic discourse) but also seeing the greatest hike in people following his page (see Figure Five), of all the political leaders.

\section{PERSONA AND THE CAPTURED IMAGE: INTERCOMMUNICATION BETWEEN REPRESENTATIONAL AND PRESENTATIONAL MEDIA PRODUCTION TECHNIQUES}

The ubiquitous presence of mobile phone cameras makes the visual display of self in still images a vital dimension of SNS persona creation. Every person encountered by the political leader when campaigning is a potential photographer, redefining long established representational media methods and techniques for image capture. Campaigns are staged activities-linked together, planned pseudo-events-specifically aimed at getting the media to circulate the image of the political leader, with photographs aimed at capturing both their authority and their authenticity. During the short campaign, three types of pictures dominated Facebook and Twitter uploaded picture galleries. The first was professional high quality images by an employed member of the party marketing team, with the photographer directly uploading to SNS with identifiable routine. Secondly, members of the marketing team created image/picture blends following structural techniques of the meme (Me-Make), which are a recognisable part of SNS display and audience participation. Finally, pictures taken by the microelectorate-particularly selfies-were shared. While focusing on those images uploaded directly to the leaders' media galleries and thus afforded permanent visibility, it is worth noting that many more pictures taken by both members of the public and the press were also shared or retweeted, making them a part of more transient timeline display. 
Figure Four: Uploaded Still Images on Facebook and Twitter

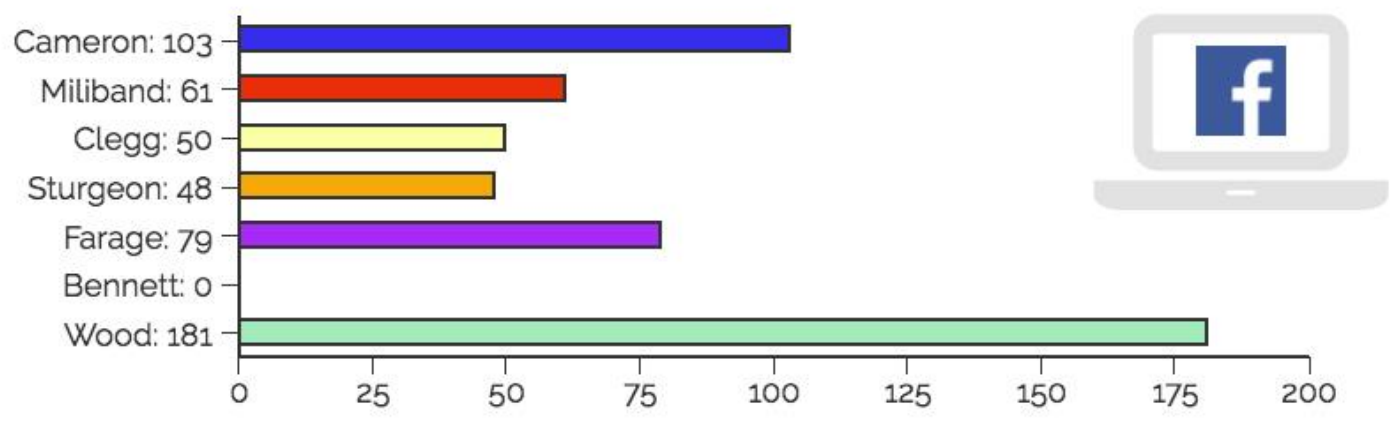

\section{\% Featuring Political Leader}
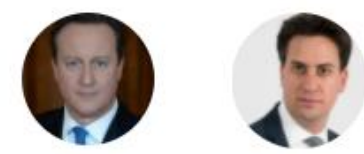

$80 \%$

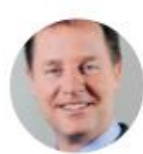

$94 \%$

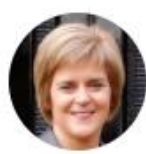

$94 \%$

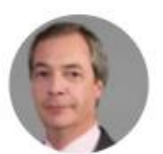

$65 \%$

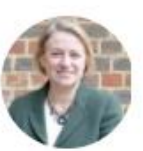

N/A

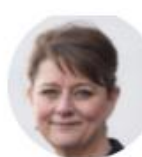

$88 \%$

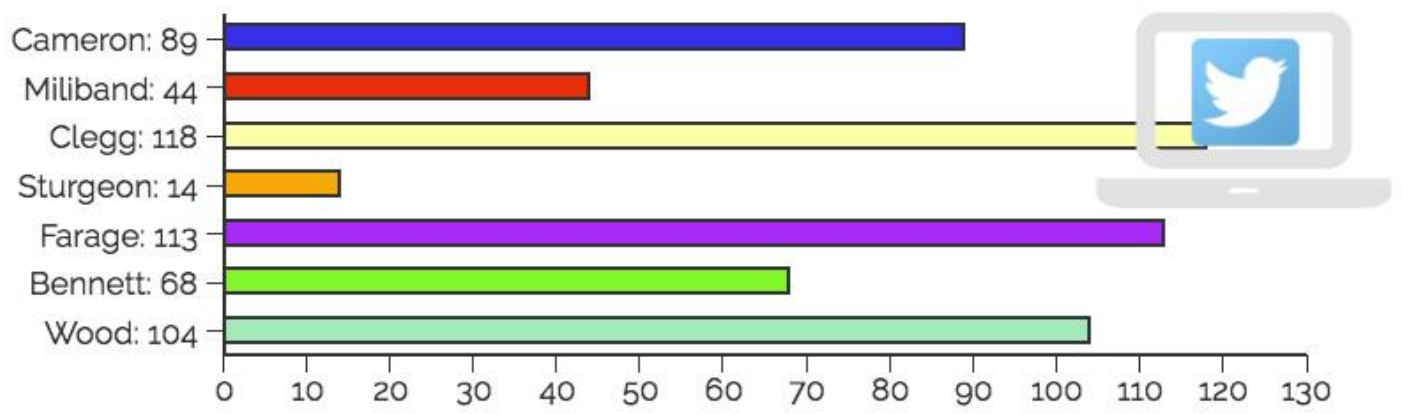

\section{\% Featuring Political Leader}

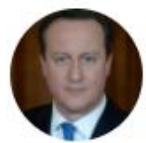

$75 \%$

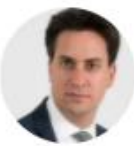

$14 \%$

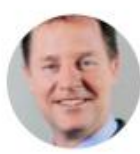

$73 \%$

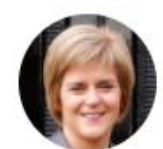

$86 \%$

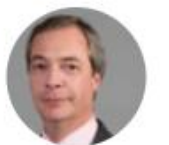

$55 \%$

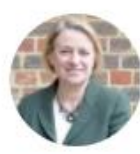

$50 \%$

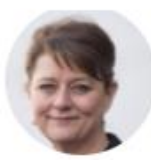

$58 \%$

It is not surprising that pictures of the leaders usually dominated their personalised SNS pages, as shown in Figure Four. Indeed, avatars are a first access point for all SNS profiles and so the captured image of the leader is a consistent presence. For four out of the seven (exceptions Farage, Bennett and Wood), uploaded images were usually professionally taken. These followed long established conventions and techniques of photojournalists covering campaigns and were often uploaded shortly after the public facing campaign moment had taken place. Attempting to capture unguarded moments of authenticity, during the staged activity of campaigning, is key to photojournalist coverage. Edwards (681-697) explores how press photography during election time contributes to political illusionism. He argues that the newspaper photograph has special 
resonation for the public as "an easily stabilized and repeated representation of people and their actions" (683). Photojournalism of electioneering finds its credibility in the successful use of "past success as a news formula" (Bennett 14), often reducing "complex issues and circumstances to memorable but simplistic visual frames" (Zelizer 1). Co-opting the way photojournalists act as witnesses to authenticity through the capture of off-guard moments means image handlers can circumvent the influence of mainstream news media, choosing which pictures work best to "frame the subject in a positive light and to promote a strategic image" (Marland 214). While, appearing to be taken on mobile phones rather than by a professional photographer, Farage and Wood's SNS profiles included images which used the structural techniques of photojournalism's coverage of campaigning, if not the high-tech kit. Bennett's profile only shared pictures taken by Green activists and, indeed, none were uploaded directly to her Facebook throughout the campaign. The lack of a professional photographer reflects differences in the campaigning budgets of these parties as compared to the other four.iv

However, as Figure Four shows, there was nervousness about using pictures of Ed Miliband, even on his own SNS profile pages. Miliband's physical appearance was regularly subject to ridicule-particularly in tabloid newspapers-throughout his tenure as Labour leader and this may well have influenced this decision. Indeed, many pictures that were shared featured the back of his head while talking to others and Labour's most dominant use of images was image/text hybrids following the construction patterns of memes. Audience generated memes have become a significant dimension of SNS construction and work well to instantly communicate an idea within the scrolling functions of Facebook and Twitter. In his recent study of how memes work as part of digital self-construction, Shifman argues they are "genres governed by dimensions of truth and temporality which have emerged as governing logics in an era marked by an amalgamation of digital photography and participatory culture" (342). While Shifman identifies they are normally whimsical, the way they are employed as part of political communication reflects his examinations of standardised content and form, the way they aim to demonstrate "stance," and how they are now circulated, imitated and transformed (343). Of the sixty-one pictures uploaded on Miliband's Facebook page, thirty-nine (64\%) were memes. Designs included text of policy alongside symbolic images of Labour (such as the red rose) or over-laid on a photograph of Miliband either from behind or at a distance. However, all the leader's pages at some point used memes' textual and performative dimensions to communicate political ideas. They blur lines between production and consumption of content, representing a new amalgamation of digital media forms into the patterns and routines of political marketing. Memes are usually audience generated. Yet, when the memes created by the marketing teams of the parties were shared, they too became part of a wider, audience-led genre.

This blurring of audience production and consumption with professional marketing practices also occurs in the way selfies appeared on leaders' pages. The fact Sturgeon's pages used her image most - and the way the term selfie was a term in textual discourse on Twitter as visualised in Figure Two-reflects the way the SNP team used selfies with clear routine. As Jerslev and Mortensen demonstrate, selfies are part of the world of digital intimacy identified by Marwick and boyd as key to the creation of online fame. In their examination of celebrity selfies, they argue they are a performative practice relying on the perception of backstage access. Busetta and Colandonato argue that the selfie should be understood as an important vernacular media production, influenced by "a larger series of techno-social practices" (2) as part of the building of celebrities' self-brand or politician's public visibility. All political leaders allowed selfies to be taken of them with members of the public during the short campaign. However, only Sturgeon's team followed a consistent pattern in their use; namely, as a strategy for constructing her political persona. There were usually two lenses on her during selfie moments. The was that of a mobile phone belonging to a member of the electorate she met in person 
during campaigning, with the picture taken either by her or by them. These were mutually beneficial interactions demonstrating mutuality of stance for promotion of self. Sturgeon demonstrated her popularity using the audience member as if a fan. In return, the individual she posed with was rewarded with an image with someone famous, to circulate on their own SNS. This has the associated reward of increased visibility through retweets, shares or increased followers. The second lens on Sturgeon was that of the SNP's official press-style photographer, capturing selfie moments from afar and uploading to her Twitter profile using the hashtag "selfie." This combination of representational and presentational media practices as a means to create the image of a leader in relation to the public reflects the potency of selfies as selfbranding activities. It also illuminates how political campaigning teams aim to create the illusion of unguarded backstage access through capturing a public moment, and as a means towards persona creation.

\section{CONCLUSION}

SNS offer what Goffman might have described as a "front", or "expressive equipment' (Presentation of Self 13-14) for persona performance as mediatised spectacle. Marketing professionals are afforded greater control over the public image of the leader-and are even able to produce content in their voice-with focused routine. The trick for campaign teams is to produce content that communicates quickly during the scroll of a social media timeline, allowing for instant identification rather than encouraging prolonged thought. Teaming personal narratives with political policies, the well-established constructions and conventions of campaign news coverage via newer digital storytelling practices helps create multidimensional, but also concentrated, political personas. SNS offer multiple routes for microelectorates to engage with political leaders. These sites encourage participation in maintaining the visibility of their branded identities through comments, shares and likes, resulting in the potential for increased followers.

\section{Figure Five: Increases in sustainable user engagement}

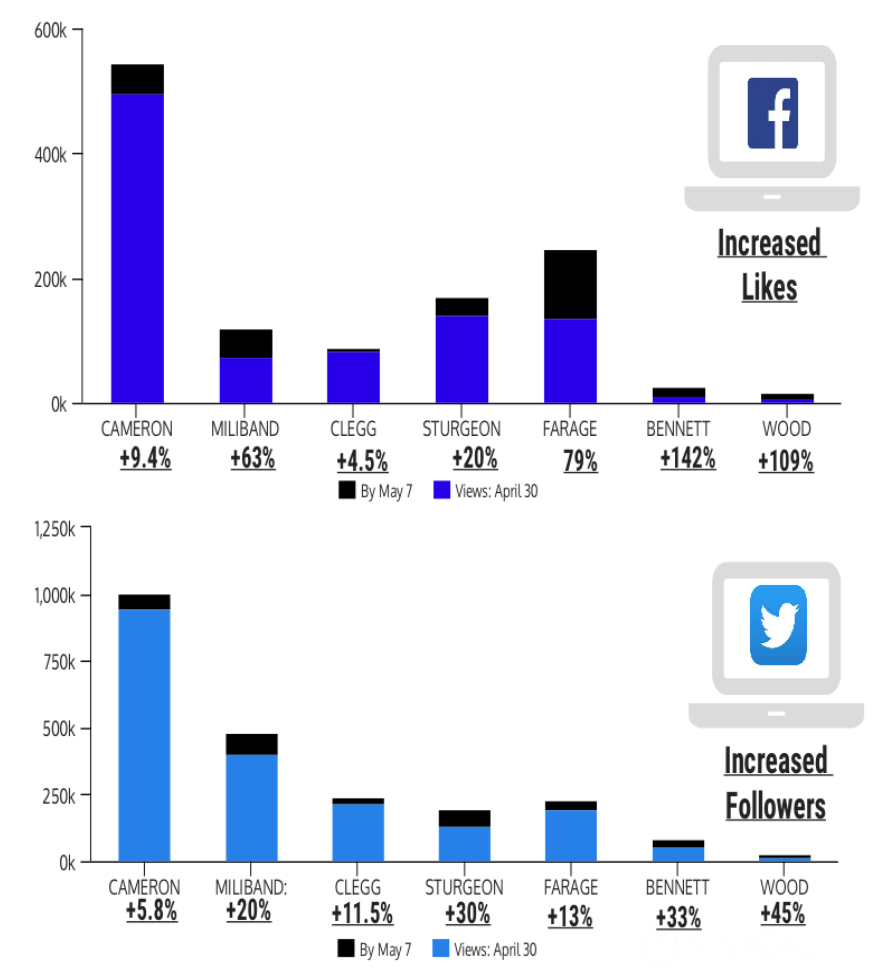


Tracking likes, shares, and increased followers allows the campaign team an almost immediate understanding of how successful a moment of online persona construction is in terms of resonance with microelectorates. This has two consequences: discourse which gets high clicks and likes provides templates for how personas are developed, managed and maintained; and, like for many other public figures, SNS have become inescapable institutions for maintaining public visibility. Figure Five demonstrates how successful the campaigns were in terms of encouraging microelectorate members to choose direct, regular access to political leaders through "following" or "liking" their SNS pages. It is this that appears the aim rather than encouraging meaningful discussion, which reflects Kriess' argument that the potential for dialogue with the politician is limited (118-135).

However, the communicative value of increased followers for democratic practice and the extension of message is significant. The leaders of the smaller political parties made real gains, reaching greater numbers of voters. However, this was still only a fraction of David Cameron's followers. Cameron's relatively small increase by percentage, despite the Conservatives having the largest budget and most consistent production patterns of all parties, suggests there are saturation points for SNS visibility. The ability of campaigning teams to expand visibility of longer standing political leaders using current production processes is limited. On Facebook, this trend continues. Cameron and Miliband had greater reach due to preexisting levels of followers and this reflected their sustained visibility in mainstream media as prime minister and leader of the opposition. However, Farage's 'likes' were almost triple those for Cameron during the short campaign. His digital dog-whistling, which teamed nationalism with fear and distrust of both establishment institutions and immigrants, resonated with Facebook audiences particularly. This had extended benefit during the EU Referendum campaign the following year, as these themes were formed the basis of the Vote Leave campaign in both mainstream media and on his social media account. However, Farage's approach had many detractors, both on SNS and in news media. Greater examinations of the ways microelectorates act synoptically — such as through direct challenges to statements of opinion or through the use of ridicule of ideas or appearance-and its potential to undermine political authority and authenticity is needed to fully understand the role of SNS in political communication.

Marshall, Barbour and Moore argue that for persona creation a new "cultural politics is emerging which is quite different from that supported by purely representational media forms" (291). Digital and personalised storytelling techniques and representational media construction patterns converge and are reshaped, offering ever-new models for persona construction. Electioneering on SNS is based around the leader's image, but is group activity, using the political persona as a networked, branded self to direct audiences to action. Looking to the successes of the Conservatives in terms of the election vote shows that their model of sustained, highly professionalised and resourced SNS production to construct Cameron's page supported success. However, the way Farage engaged in digital dog-whistling to attract the attention of SNS users and mainstream media offers a clear framework for how leaders can use SNS to construct a persona which increases both their own and party visibility. The perpetual change of party leaders-only Sturgeon and Wood survived both this election and the Brexit vote the following year-means political marketers must start constructing different leaders' SNS personas in relatively rapid succession. Understanding what has worked previously to quickly build visibility means that successes achieved through certain means, such as Farage's digital dog-whistle politics, may be ever more seductive techniques for those involved in constructing and using persona as promotional activity. 


\section{ENDNOTES}

i. Each political party also had a YouTube channel used primarily as a dissemination tool to provide video content on the leader's profile pages. Video is not included within this study.

ii. Australian Lynton Crosby was engaged by the Conservatives in 2012 and then joined the following year by Jim Messina from the Barack Obama campaign team. American David Axelrod-who, along with Messina, engineered Obama's successful 2008 and 2012 presidential campaigns-was hired by Labour in 2014. The Liberal Democrats employed South African Ryan Coatzee in 2012 to serve first as special advisor to Nick Clegg and then strategic director for the 2015 short campaign, while Ruwan Kodikara, from the Quiller consultancy, assumed the role of head of media and branding. UKIPs' campaign was led by former BBC journalists Paul Lambert and Alexandra Phillips, with assistants. Both Bennett and Wood replied to questions by the researcher on Twitter about their teams, which numbed fewer than four. Kevin Pringle, an old ally of Alex Salmond, spearheaded the SNP campaign. Peter Murrell, party chief executive, acted as Head of Communications. Total spend for each political party for GE campaign 2015 in descending order: Conservatives: $£ 15.6 \mathrm{~m}$; Labour: $£ 12.1 \mathrm{~m}$; Liberal Democrats: $£ 3.5 \mathrm{~m}$; UKIP $£ 2.9 \mathrm{~m}$; SNP: £1.5m; Greens £1.131m; Plaid Cymru: £97,139 (Source: Chorley, M. 'How Much Does it Cost to get an MP elected.' The Times, Jan 20 2016).

iii. Cameron was the lowest, using 282 different words in tweets. The highest was Natalie Bennett's use of 815 different words during the last week of the campaign. Ed Miliband used 289 different words.

iv. See above.

\section{WORKS CITED}

Arnould, Eric, Linda Price, and George Zinkhan. Consumers. New York: McGraw-Hill Higher Education, 2003. Print.

Auty, Caroline and Alison Cowen. "Political parties on the Net - 4 years closer to cyber-utopia?" Aslib Proceedings 53.9 (2001): 340-352. Print.

Barbour, Kim, and P. David Marshall. "The academic online: constructing persona through the World Wide Web." First Monday 17.19 (2012). Web.

Baxter, Graeme, Rita Marcella, Denise Chapman, and Alan Fraser. "Voters' information behaviour when using political actors' web sites during the 2011 Scottish Parliament election campaign." New Information Perspectives. 65.5 (2013): 515-533. Print.

Bennett, Lance. News: The Politics of Illusion. New York: Longman, 1988. Print.

Bennett, Natalie. https://twitter.com/natalieben (Account Created: Oct 2008)

--- https://www.facebook.com/GreenNatalieBennett (Account Created: Sep 2012)

Bell, Matthew. "Election 2015: Is this the first social media campaign?" Channel 4 News website. (2015). Web.

Bucholtz, Mary, and Kira Hall. "Identity and interaction: A sociocultural linguistic approach." Discourse Studies 7 (2005): 585-614. Print.

Busetta, Laura, and Valerio Coladonato. "Be Your Selfie: Identity, Aesthetics and Power in Digital Self-Representation" Networking Knowledge 8.6 (2015): 1-6. Web.

Cameron, David. https://twitter.com/David Cameron (Account Created: Jan 2010)

--- https://en-gb.facebook.com/DavidCameronOfficial/ (Account Created: Sep 2013)

Clegg, Nick. https://twitter.com/nick clegg (Account Created: Jun 2008)

--- https://www.facebook.com/nickclegg/ (Account Created: Mar 2008)

Corner, John, and Dick Pels. Media and the Restyling of Politics: Consumerism, Celebrity and Cynicism. London: Sage, 2003. Print. 
Coleman S. "Elections as storytelling contests", Contemporary Theatre Review. 25.2 (2015): 166176. Web. http://opensample.info/elections-as-storytelling-contests

Coupland, Justine, and Nikolas Coupland. "Attributing stance in discourses of body shape and weight loss." Stance: sociolinguistic perspectives. Ed. Alex Jaffe. Oxford: Oxford University Press, 2009. 227-249. Print.

Damari, Rebecca. "Intertextual stancetaking and the local negotiation of cultural identities by a binational couple." Journal of Sociolinguistics 14.5 (2010): 609-629. Print.

Debord, Guy. The Society of the Spectacle. New York: Zone Books, 1967. Trans. Nicholson Smith, 1994. Web.

Downs, Anthony. An Economic Theory of Democracy. New York: Harper and Row, 1957. Print.

Du Bois, John.W. “The stance triangle." Stancetaking in Discourse: Subjectivity, Evaluation, Interaction. Ed. Robert Englebretson. Amsterdam: Benjamins, 2007. 137-182. Print.

Edwards, Janis. "Visual Literacy and Visual Politics: Photojournalism and the 2004 Presidential Debates." Communication Quarterly 60.5 (2012): 681-697. Web.

Farage, Nigel. https://twitter.com/Nigel Farage (Account Created: Jan 2009)

--- https://www.facebook.com/nigelfarageofficial (Account Created: Sep 2010)

Gibson, Rachel, Marjorie Margolis, Danielle Resnick, and Stephen Ward. "Election campaigning on the WWW in the USA and UK: a comparative analysis." Party Politics: 9.1 (2003): 4775. Print.

Gibson, Rachel and Stephen Ward. "An outsider's medium? The European elections and UK party competition on the Internet." Journal of Elections, Public Opinion \& Parties 10.1 (2000): 173-191. Print.

Giddens, Anthony. Modernity and Self-Identity. Standford: Stanford University Press. 1991. Print. Giles, David, Psychology of the Media. Basingstoke: Palgrave, 2010. Print.

Goffman, Erving. The Presentation of Self in Everyday Life. Edinburgh: University of Edinburgh Social Sciences Research Centre, 1956. Web.

---. The Characteristics of Total Institutions. Paper: Walter Reed Institute, 1957. Web.

Hearn, Alison. "Producing "Reality" Branded Content, Branded Selves, Precarious Futures."

Companion to Reality Television: Theory and Evidence. Ed. Laurie Ouellette, Somerset, NJ: John Wiley \& Sons, 2013. Print.

---. “'Sentimental 'Greenbacks' of Civilization': Cartes de Visite and the Pre-History of SelfBranding”, The Routledge Companion to Advertising and Promotional Culture. Ed. Matthew McAllister and Emily West. New York: Routledge, 2013. Print.

Horton, Donald, and Richard Wohl. "Mass Communication and para-social interaction: observations on intimacy at a distance'" Psychiatry, 19 (1956): 213-229. Web.

Jankowski, Nicholas, Kristen Foot, Randolph Kluver, and Steven Schneider. "The Web and the 2004 EP election: comparing political actor web sites in 11 EU Member States." Information Polity 10.3 (2005): 165-176. Print.

Jerslev, Anne, and Mortensen Mette. "What is the Self in Selfie? Celebrification, phatic communication and performativity." Celebrity Studies 7.2 (2016): 249-263. Web.

Kellner, Douglas. "Media Spectacle: Presidential Politics, and the Transformation of Journalism." The Routledge Companion to News and Journalism. Ed. Stuart Allen, Oxon: Routledge, 2010. 116-126. Print.

Kriess, Daniel. "Digital Campaigning.” Handbook of Digital Politics. Ed. Stephen Coleman and Deen Freelon. Cheltenhem: Elgar, 2015. 118-135. Print.

Mackey, Steve. “Persona - an old public relations problem?” Persona Studies 2.1 (2016): 84-96. Web.

Marland, Alex. "Political Photography, Journalism and Framing in the Digital Age." Press/Politics 17.2 (2012): Web.

Marshall, P. David. Celebrity and Power: Fame in Contemporary Culture. Minneapolis: University of Minnesota Press, 1997. Print.

---. "The Promotion and Presentation of the self: celebrity as marker of presentational media." Celebrity Studies 1.1 (2010): 35-48. Web.

---. "Mapping the proliferation of the public self." Journalism 15.2 (2014): 153-170. Print. 
Marshall, P. David, Christopher Moore and Kim Barbour. "Persona as method: exploring celebrity and the public self through persona studies." Celebrity Studies 6.3 (2015): 288305. Web.

Marwick, Alice. "You May Know Me from YouTube." A Companion to Celebrity. Ed. Sean Redmond and P. David Marshall. Chichester: Wiley Blackwell, 2015. 333-349. Print.

Marwick, Alice, and danah boyd. "I tweet honestly, I tweet passionately: Twitter users, context collapse, and the imagined audience." New Media \& Society 13.1 (2011): 114-133. Print.

---. "To See and Be Seen: Celebrity Practice on Twitter", Convergence 17.2 (2011): 139-158. Print.

McLuhan, Marshall. Understanding Media. London: Routledge, 1964 (2003 reprint). Print.

Miliband, Ed. https://twitter.com/Ed Miliband (Account Created: Jul 2009)

--- https://www.facebook.com/edmiliband/ (Account Created: Jul 2010)

Meyer, Thomas, and Hinchman, Lew. Media Democracy: How the Media Colonize Politics. Cambridge: Polity, 2002. Print

Michael, Bethan. "Social media, identity and democracy." Media/Democracy. Ed. Alex Charles. Newcastle: Cambridge Scholars Publishing, 2013. 29- 47. Print.

Papacharissi, Zizi. "Without you, I'm nothing: performances of the self on Twitter." International Journal of Communication 6 (2012): 1989-2002. Web.

Rojek, Chris. Fame Attack: The Inflation of Celebrity and its Consequences. London: Bloomsbury, 2012. Print.

Ross, Karen, Susan Fountaine and Margie Comrie. "Facing up to Facebook: politicians, publics and the social media(ted) turn in New Zealand." Media, Culture \& Society 37.2 (2015): 251-269. Web.

Schumpeter, Joesph. Capitalism, Socialism and Democracy. London: Allen \& Unwin, 1976. Print.

Senft, Teresa. Camgirls: Celebrity and Community in the Age of Social Media. New York: Peter Lang, 2008. Print.

---. "Microcelebrity and the Branded Self." A Companion to New Media Dynamics. Ed. John Hartley, Jean Burgess, and Axel Bruns. Oxford: Wiley Blackwell, 2013. Web.

Shifman, Limor. "The Cultural Logic of Photo-based Meme Genres." Journal of Visual Culture 13.3 (2014): 340-358. Web.

Street, John. 'The Celebrity Politician: Political Style and Popular Culture." Media and the Restyling of Politics: Consumerism, Celebrity and Cynicism. Ed. John Corner and Dick Pels. London: Sage, 2003. Print.

Sturgeon, Nicola. https://twitter.com/NicolaSturgeon (Account Created: Jun 2010)

--- https://www.facebook.com/NicolaSturgeonSNP (Account Created: May 2013)

Thomas, Sarah. "Celebrity in the 'Twitterverse': history, authenticity and the multiplicity of stardom situating the 'newness' of Twitter." Celebrity Studies 5.3 (2014): 242-255. Web.

Tolson, Andrew. "Hope Springs Eternal?: The Illusions and Disillusions of Political Celebrity." A Companion to Celebrity. Ed. Sean Redmond and P. David Marshall. Chichester: Wiley Blackwell, 2015. 161-176. Print.

Tuchman, Gaye Making News: A Study in the Construction of Reality. New York: The Free Press, 1978. Print.

Turner, Graeme. Understanding Celebrity. Los Angeles: Sage, 2013. Print.

Usher, Bethany “Twitter and the Celebrity Interview." Celebrity Studies 6.3 (2015): 306-321. Web.

Wernick, Andrew. Promotional Culture: advertising, ideology and symbolic expression. London: Sage, 1991. Print.

Wood, Leanne. https://twitter.com/LeanneWood (Account Created: Apr 2008)

--- https://www.facebook.com/leanne.wood.714/ (Account Created: Apr 2008)

Zelizer, Barbie. About to Die: How News Images Move the Public. New York: Oxford University Press, 2010. Print.

Editor's note: This article was updated on 20 December 2016 at the author's request to correct minor statistical errors in Figure 2 (p. 30) and Figure 4 (p. 35). 